\title{
Framework and Strategy of Customer Relationship Management System in Electronic-Commerce
}

\author{
Liping $\mathbf{L i}^{\mathbf{1 2}}$ \\ Information College, Yunnan University of Finance and Economics, 650000 Kunming, China \\ E-mail: I Iplrs@126. com

\section{Xiaosong Wu} \\ Information College, Yunnan University of Finance and Economics, 650000 Kunming, China \\ E-mail: 1403044553 @qq. com
}

\begin{abstract}
At present, the status of electronic-commerce in the economic and social development is upgraded and e-commerce is playing a more and more important role in the social and economic life. It has become an important driving force for the world economic development in the $21^{\text {st }}$ century. With the change of the market structure, the enterprise management mode has changed from the mode of "taking the product as the center" to that of "taking the customer as the center" while the customers are the very valuable resources of the enterprises because they are related to the survival and development of enterprises. In order to maintain the customers' loyalty, retain and develop customers, and gain more profits, the operation of enterprises should proceed from the needs of customers; as a result, the customer relationship management -- CRM is particularly important and doing CRM in e-commerce is a pressing matter of the moment. This paper introduces the core idea of CRM in e-commerce, the architecture of CRM system, the functions of each subsystem and the application of data warehouse, data mining and cloud computing technology in e-commerce CRM; and this paper also points out the development trend and prospect of e-commerce CRM.
\end{abstract}

\footnotetext{
${ }^{1}$ Speaker

${ }^{2}$ Corresponding Author
} 


\section{Introduction}

With the rapid development of economy and increasingly rich social products, the enterprise management mode has changed from the "product-oriented" to "customer-oriented" mode and the customers have become the extremely valuable resources for enterprises because they are related to the survival and development of enterprises, whose operation should meet the customer's requirement so as to maintain the customers' loyalty, retain and develop customers as well as make the enterprise to obtain more profit. In order to achieve the above purpose, it needs to do a good job of customer relationship management -- CRM. In my reference literature, some literature has carried out the theoretical research, such as the principle and application of customer relationship management, which studied the theory and method of customer relationship management from the perspective of management, but failed to involve the network application; some literature has mad a detailed analysis of CRM to a specific enterprise, such as $H P$ customer relationship management, which showed the management method and characteristic of the Hewlett-Packard, but failed to provide a general pattern; some literature research has analyzed the design and practice of CRM, such as the principle of CRM, design, practice, which studied the network design of CRM but had to be more perfect and comprehensive in the frame. This paper studies CRM under the environment of electroniccommerce in hopes that a general framework and some personal views and opinions can be provided.

\section{CRM in E-Commerce}

CRM in e-commerce is a system to gain, maintain and increase profitable of customers [1]. It has advanced the management ideas and techniques. It can integrate resources, business and technology effectively. It can enable the enterprises to cut down cost, increase efficiency, build one-to-one marketing mode based on learning, and allow enterprises to maximize their customer satisfaction and loyalty, retain existing customers, develop new customers, explore and grasp valuable customers who can bring maximum values. It provides new business management strategy of modern enterprise and helps enterprise get survival and development in the furious competition

\section{Construction of CRM System in E-Commerce}

\subsection{The Needs of CRM System in E-Commerce}

CRM in e-commerce is not a simple sum of e-commerce and customer relationship management, but applies reasonably core ideas of CRM to e-commerce. It is a kind of advanced management system which can get rid of limitations of the traditional CRM. It should have the following requirements: firstly, it should provide the marketing automation, sales automation and service automation under the environment of e-commerce, and connect the three well; secondly, it should broaden the communication channels of customers by technical means (direct contact, telephone, fax, email and webpage, etc.); thirdly, it should provide a unified customer data warehouse to store customer data, product data and partner data; fourthly, it should have the ability of integration with other application systems. It should have the interface of ERP/ERM/SCM (Enterprise Resource Planning/Enterprise Resource Management/Supply Chain Management). It should be connected with marketing, service, production and research to avoid the separation of each department under the traditional environment[2]. 


\subsection{Structure and Function of CRM System in E-Commerce}

The main functions of CRM system in e-commerce are shown as follows: firstly, the automation of sales, marketing and customer service; secondly, the integration/automation of means (telephone, fax, e-mail, and network) for communication with the customer; thirdly, the analysis and processing of information or data warehouse information that is accumulated from above two parts, and the results of analysis and processing can be used in the business intelligence, the partner management and the decision of enterprises[3]. The structure of CRM system is shown in Fig.1.



Figure 1: Structure of CRM System in E-commerce

\subsubsection{Marketing Automation/MA}

Marketing automation, as technical assistance marketing, helps designing, implementing and evaluating the marketing behavior (traditional marketing behavior and network marketing behavior) and relevant activities in e-commerce environment[4]. It helps marketers do planning, execution, monitoring and analysis for the marketing activities directly. It can also use work-flow technology to optimize the marketing process and make automation of some common tasks and process. The sub function modules of marketing automation are:

\subsubsection{Campaign Management}

This module can design and implement a single channel or multi-channel marketing activities (including the traditional marketing and the network marketing), track customer's feedback in respect of these activities and be also extended to the sales department to plan and execute the sales activities.

\subsubsection{Marketing Content Management}

This module can check the implementation of marketing activities, evaluate the benefit of marketing activities, coordinate various marketing channel, and prevent the conflict between different marketing channels. 


\subsubsection{Marketing Analysis}

This module can analyze the marketing activities, support collection, control and screening to the marketing data, make a report and analysis of the results in time, make data and related information to be distributed to various sales channels and decision-making departments invarious forms, and further improve the marketing strategy. The marketing automation module is shown in Fig.2.

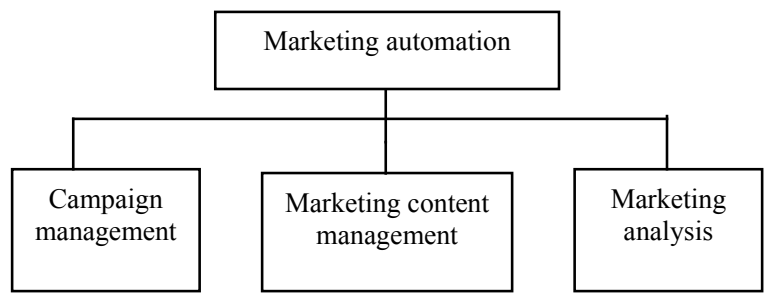

Figure 2: Composing of the Marketing Automation Module

\subsubsection{Sales Automation/SA}

The sales automation is also known as the technical assistance sales. It is the basic module and the most important part of CRM. The sub function modules of Sales automation include:

\subsubsection{Sale Force Automation}

In the e-commerce, the sale force automation is a highly integrated module. It contains a wide range function of sales, mainly including the contact management, the sales opportunity management and the sales forecast management, etc.; in which, the contact management integrates various contact channels to provide perfect customer contact information management. The function of sales opportunity management is looking for opportunities that could bring revenues to the company (events or customers) and the sales forecasting management helps the salesmen track customers, know the sales quota, analyze the sales status and forecast the future income; in addition, the sale force automation also includes activity management, price management, calendar management, report management, expenses reimbursement management and commission management, etc[5].

\subsubsection{Sale Configuration Management}

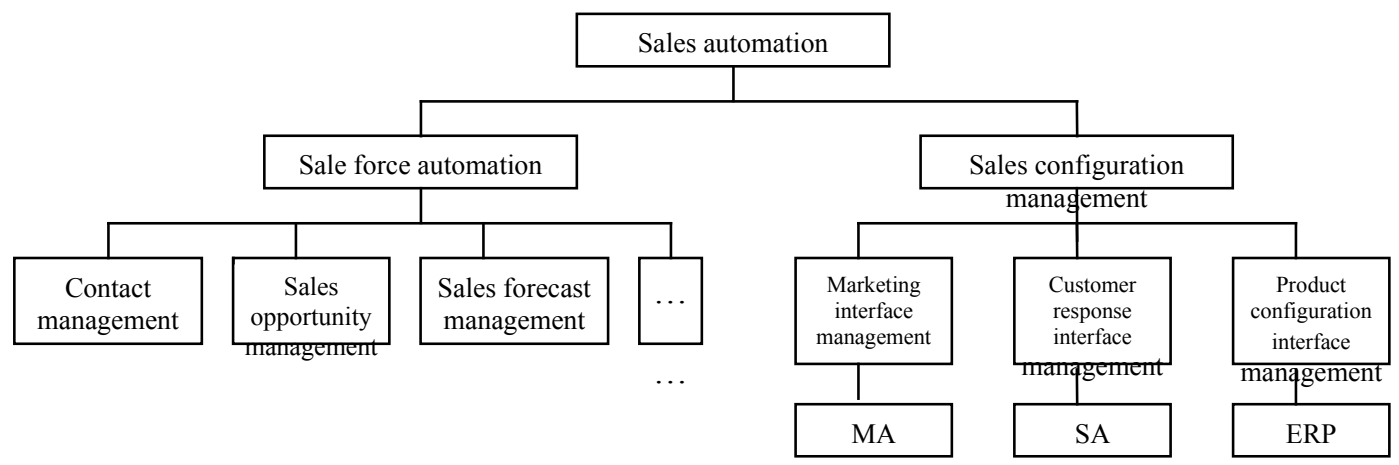

Figure 3: Composing of the Sales Automation Module

The sales configuration management mainly provides interface of sale force automation with other modules. It mainly has the following interface management: firstly, management of the marketing interface, which is an interface connected with the marketing system to allow the sale force automation module to receive the results of marketing automation module and receive 
information about competition, competitor analysis and competition strategy, etc. The information is made by the business intelligence module; secondly, management of the customer response interface, which makes departments (such as call centers) to carry out queries and responses of trading records, and track the services. It is connected with the service automation module/SA; thirdly, management of the product configuration interface, which makes the reception-sales data back to the back-end (such as enterprise resource planning /ERP), thus the reception-sales can guide back-end research. It can improve the enterprise's workflow. This module is connected with the enterprise resource planning/ERP. Sales automation module is shown in Fig.3.

\subsubsection{Customer Service Automation/CSA}

\subsubsection{On-site Service}

The main users of on-site service are the on-site service personnel. They access the on-site service module of CRM by network. It includes two parts: firstly, the management that contact directly with the customer, such as the service request management, the repair management, the quality management, the contract management, the order and invoice management, etc.; secondly, the management that doesn't contact directly with the customer, such as the asset management, the personnel management and the knowledge management, etc.

\subsubsection{Call Center}

The call center is a comprehensive customer service and marketing center that features very rich type of business. It can be accessed by multiple media channels such as telephone, fax, Internet, email, video, etc.; besides, it can also collect the customer information, understand the needs of customers, solve the customers' problems and meet the needs for personalization. The aim of such call center is to enhance the customer satisfaction and loyalty. The core of the call center is CTI (Computer Telecommunication Integration) server, a computer connected with the switch[6]. As it organically combines the telephone exchange system with computer system, supports the channel switching functions and data processing functions, it can not only receive the call information from the switches (such as call telephone number) but also control the call of switches such as call transfer, call termination, intelligent call, etc. The structure of call center is shown in Fig.4.

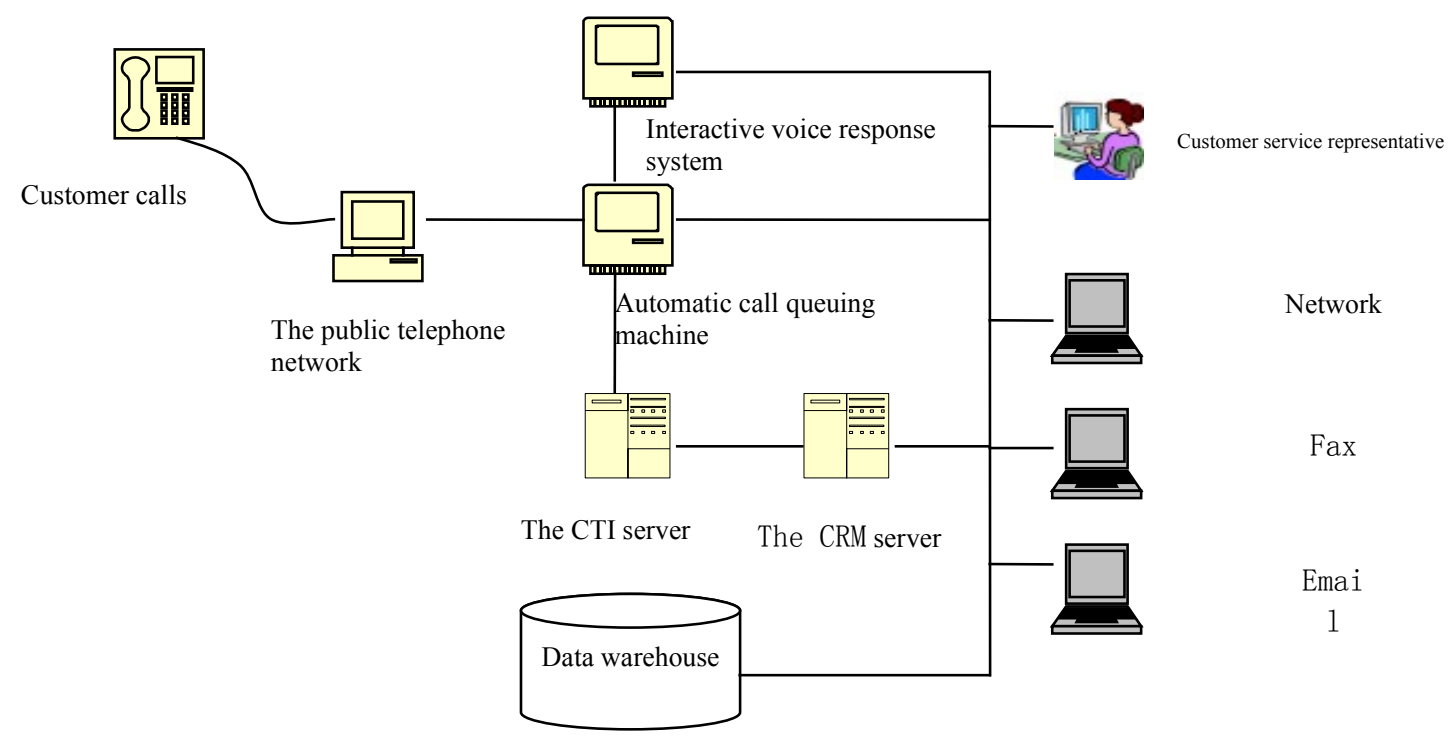

Figure 4: Structure of the Call Center 


\subsubsection{Network Self Service}

The network self service is a form of service that the enterprise uses the internet technology to provide a round-the-clock "do-it-yourself" (DIY) service in e-commerce environment. It is applied to the pre-sales, sales and after-sales service. It allows customers to enjoy the service at any time and any place while helping improve the customer relationship and increase the customer's satisfaction.

\subsubsection{Data Warehouse}

The data warehouse is under the condition that a lot of databases already exist. It is produced in order to make the policy decision and dig more data resources. It is not a large database but a data collection that is subject-oriented, integrated, relatively stable, and capable of reflecting the historical changes. It includes the following parts:

\subsubsection{Customer Interaction Data Mart}

The enterprises use it in the process of customers purchase to develop cooperation relationship between enterprises and customers because it provides the basis of mutual understanding for enterprises and users, makes the enterprises to grasp customers' information more accurate, helps the enterprises to understand the customers' needs, provides data support for the marketing management; at the same time, it integrates the business intelligence with stores and manages the customers' data, analyzes the customers' data by a variety of statistical data analysis tools and provides the analysis reports, such as the customer value evaluation, customer satisfaction evaluation, service quality evaluation, marketing effect evaluation, the future market demand etc[7]. It provides decision information for a variety of business activities. The data thereof should reflect the following contents: the marketing environment and its change, the marketing concept and its change, the enterprise core value and its changes, the way of marketing and its change, management mode and its change based on information technology.

\subsubsection{Customer Data Mart}

The data thereof is dynamic. It helps enterprises to grasp and understand the customers' behavior as well as provides data support for the marketing management. It includes the following information: the customer's basic information, purchase information, service information, preference information, browse information etc., which comes from business transaction system, marketing system, call center and data flow as generated by click.

\subsubsection{Product Data Mart}

It records the product information throughout the life cycle of products, such as product design, product reviews, product approval, product manufacture, product launch, product change and work-flow optimization etc. It tracks and records each process in the life cycle of the products, helps the enterprises to improve product quality, optimizes materials and resources allocation, reduces the cost to win more customers.

\subsubsection{Partner Data Mart}

Partners can bring enterprises with capital resources, advanced technologies and management experiences, which can give enterprises the ability to enhance their core competitiveness and expand the market; at meanwhile, the two parties can share risks and information. They can develop and carry out creation together to realize the sharing of resources and complementary advantages. The partner data mart can also help enterprises to find the best cooperation according to the situation, realize the customized service and bring more value to the customer. The information of the partner data mart includes: the partner's condition of technical advantages, the allocation of resources, the business management and credit, etc.

In summary, the whole operation of CRM system includes: the front desk, including onsite service and mobile sales, which can realize the marketing automation, sales automation and service automation; the call center, telephone, e-mail, fax, direct contact realizes full communication and interaction between enterprises and customers. Under the support of background data warehouse, the CRM system will complete the marketing management and the partner management while realizing the business intelligence. The CRM system will combine 
ERP/ERM, supply chain information, historical information to provide excellent products, perfect service, and meticulous care and personalized customized solutions for customers.

\section{CRM in Cloud Computing}

The cloud computing is a business computing model. It puts the computing task into resource pool that consists of a large number of computers so that the user can get calculation storage space and service on demand. In the cloud computing, the capacity of resource pool is unlimited and all the back-end services in e-commerce can be put in the resource pool so that users who want to develop e-commerce can freely choose the resources they need rather than investing a lot for purchase or development [8]. The essential of cloud computing is the optimal utilization of computing resources. As to large e-commerce enterprises, they can make good use of idle computing resources by cloud computing mode, provide cloud services for small and medium-sized enterprises in e-commerce, and small and medium-sized enterprises can also obtain resources with low cost by cloud computing mode. As far as CRM is concerned, the cloud computing can optimize the system environment, strengthen the sharing of resources, improve resource utilization, and help improve the customer satisfaction and loyalty.

\subsection{Evolution Steps of the Enterprise from IT to Cloud Computing}

The traditional enterprise IT focuses on the internal management of enterprises and supports the transactional applications because it is a tightly coupled system. Web2.0 supports interactive services because it is a loosely coupled system and it makes the traditional enterprise IT producing value-added[9]. The cloud computing makes the external market as the focus, focus on promoting competitive power of enterprise in the external market, supports the sharing services because it is a loosely coupled system. How to evolutes from IT to cloud computing? The first step, integrates, standardize and optimize the data center. The second step, realize the transformation of the data center by the virtual, storage and other means. The third step, build a flexible, dynamic IT infrastructure and realize the cloud computing.

\subsection{Basic Frame of Enterprise CRM Cloud}

The basic framework of CRM cloud computing in enterprise is mainly composed of server, network, and storage device. Cloud computing requires more intensive computation ability, such as multi nuclear structure, complete virtualization, the integration of multiple $\mathrm{I} / \mathrm{O}$, dynamic scheduling of computing resources, $100 \mathrm{Gbps}$ network performance, a flat and high scalable architecture, massive two layer acyclic network, FCOE/DCE unified switching, the depth of the L2-L7 high speed. The basic frame of Enterprise CRM cloud is shown in Fig.5

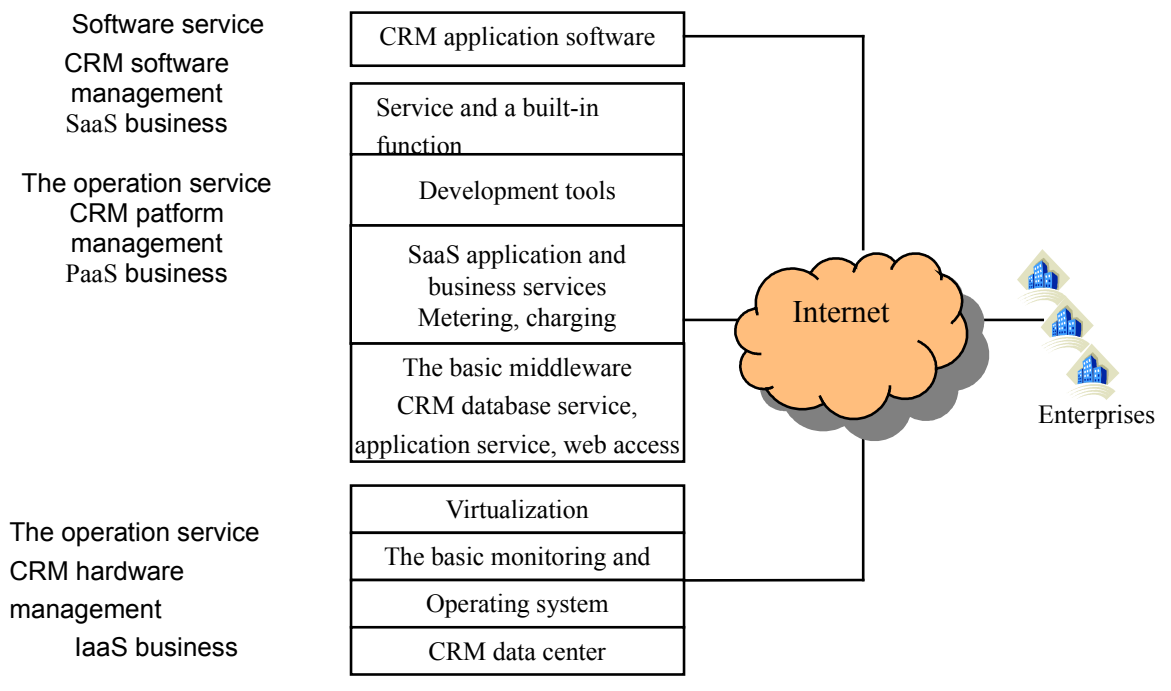


Figure 5: Basic Frame of Enterprise CRM Cloud

\section{Conclusion}

This paper analyzes the needs of CRM system in the electronic commerce, gives the composition, structure and functions of CRM system, and elaborates the application of data warehouse, data mining and cloud computing in CRM. On the basis of the former research, this paper makes the following expansion: 1. this paper puts the ERP/ERM information, knowledge management information, supply chain information into CRM system which can make the enterprises, customers, agents, manufacturers, suppliers, distributors to exchange information easily and timely, make the resources allocation and use more efficiently, make the data analysis more in-depth and make the forecast more accurately so that the customer relationship management will be more thoughtful and meticulous; 2 . this paper emphasizes the role of enterprise partners, puts the partner data mart into the CRM data warehouse in order to provide more solutions to the customers and help realize the personalized customization of customers; 3 . this paper combines the hot application, puts forward the basic framework of enterprise CRM cloud and the evolution steps of enterprise from IT to cloud computing. The composition and function of CRM system proposed in this paper has to be further improved, and there is a long way to go to establish an efficient, stable, reliable, wisdom CRM system.

\section{References}

[1] Hua Wang. The implementation of CRM in e-commerce environment [J]. Market modernization.125(2),15-18(2010) (in Chinese)

[2] Huiyi Tian. The new electronic commerce introduction: case study [M].Tsinghua University press, Beijing. pp,3-6( 2012) (in Chinese)

[3] Malhotra and Yogesh. Knowledge management for the new world of business[J].quality and participation.188(9),59-66(2010)

[4] Rongqi He. The principle of CRM, design, practice [M]. electronics industry press, Beijing.pp,12-56( 2011) (in Chinese)

[5] Jieru Zhou. Customer relationship management classic case and detailed explanation [M]. Shanghai Jiao Tong University press, Shanghai.pp, 5-22(2011) (in Chinese)

[6] Zhigang Li. The principle and application of customer relationship management [M]. Electronics industry press, Beijing. pp,3-15( 2011) (in Chinese)

[7] Xiaowei Lu. Study on the influence of customer loyalty on price sensitivity in $C R M[J]$.management engineering.156(5),24-26(2010) (in Chinese)

[8] Su Chen. The strategy of CRM in e-commerce[J].Enterprise technology development.182(6),1215(2010) (in Chinese)

[9] Dien Zhu. Customer relationship management HP[M]. People's Posts and Telecommunications Press,Beijing.pp,14-19(2012) (in Chinese) 